\title{
Resistance to Species of Phytophthora Identified among Clones of Juglans microcarpa $\times J$. regia
}

\author{
Gregory T. Browne ${ }^{2}$
}

USDA-ARS, Crops Pathology and Genetics Research Unit, Department of Plant Pathology, University of California, Davis, CA 95616

Charles A. Leslie

Department of Plant Sciences, University of California, Davis, CA 95616

Joseph A. Grant

University of California Cooperative Extension, 2101 East Earhart Avenue,

Suite 200, Stockton, CA 95206

Ravindra G. Bhat

Department of Plant Pathology, University of California, Davis, CA 95616

Leigh S. Schmidt

USDA-ARS, Crops Pathology and Genetics Research Unit, Department of Plant Pathology, University of California, Davis, CA 95616

Wesley P. Hackett

Emeritus, Department of Plant Sciences, University of California, Davis, CA 95616

Daniel A. Kluepfel

USDA-ARS, Crops Pathology and Genetics Research Unit, Department of Plant Pathology, University of California, Davis, CA 95616

Reid Robinson ${ }^{1}$

Department of Plant Sciences, University of California, Davis, CA 95616

Gale H. McGranahan

Emeritus, Department of Plant Sciences, University of California, Davis, CA 95616

Additional index words. Phytophthora cinnamomi, Phytophthora citricola, Juglans californica, Juglans hindsii, Juglans major, Juglans nigra, english walnut, persian walnut

Abstract. Species of Phytophthora are serious soilborne pathogens of persian (english) walnut, causing crown and root rot and associated production losses worldwide. To facilitate the development of improved walnut rootstocks, we examined resistance of 48 diverse clones and seedlings of Juglans species to $P$. cinnamomi and $P$. citricola. Plants were micropropagated, acclimatized to a greenhouse environment, and then exposed to the pathogens in artificially infested potting soil mix. Inoculated plants, as well as noninoculated controls, were subjected to soil flooding for 48 hours every 2 weeks to facilitate infection by the pathogens. Two to 3 months after inoculation, resistance to the pathogens was assessed according to the severity of crown and root rot. Clonal hybrids of J. californica $\times J$. regia were highly susceptible to the pathogens (means $52 \%$ to $76 \%$ root crown length rotted), while several clones of $J$. microcarpa $\times J$. regia were significantly less susceptible (means $8 \%$ to $79 \%$ crown length rotted). Among clones of other parentages tested, including: J. microcarpa, $(J$. californica $\times J$. nigra $) \times J$. regia, $J$. hindsii $\times J$. regia, $(J$. hindsii $\times J$. regia $) \times J$. regia, $[(J$. major $\times J$. hindsii $) \times J$. nigra $] \times$ $J$. regia, and $J$. nigra $\times J$. regia, responses varied, but tended to be intermediate. When 'Serr' scions were budded or grafted on $J$. microcarpa $\times J$. regia clone ' $R X 1$ ' or Paradox $(J$. hindsii $\times J$. regia) seedling rootstocks in a commercial orchard infested with $P$. cinnamomi, all trees on ' $R X 1$ ' remained healthy, whereas only $49 \%$ of those on Paradox survived. Thus, useful resistance to Phytophthora is available among J. microcarpa $\times$ $J$. regia hybrids and is evident in ' $\mathrm{RX1}$ ' rootstock.

Persian (english) walnut (Juglans regia L.) orchards can incur serious economic loss from attack by several soilborne pathogens, including Agrobacterium tumefaciens Smith and Townsend (causal agent of crown gall disease), Armillaria mellea (Vahl:Fr.) P. Kumm
(Armillaria root rot), numerous species of Phytophthora de Bary (Phytophthora crown and root rots), and several species of plant parasitic nematodes (nematode-incited root destruction or galling and debilitation). Rootstocks typically have been used for persian walnut cultivars to improve tree vigor, tolerance to salinity and waterlogging, and resistance to some pathogens (McGranahan and Catlin, 1987). Presently, about $80 \%$ of California walnut acreage is planted on Paradox seedling rootstock, which is mainly $J$. hindsii (Jeps.) R.E. Sm. $\times$ J. regia (Potter et al., 2002), while about $15 \%$ and $5 \%$ of the orchards are on Northern California black walnut (NCB) (J. hindsii) and Persian walnut seedling rootstocks, respectively. None of the rootstocks, however, is sufficiently resistant or tolerant to all of the important soilborne pathogens.

More than 10 species of Phytophthora have been implicated in Phytophthora crown and root rot on walnut, and among them $P$. cinnamomi Rands and $P$. citricola Sawada are especially aggressive and difficult to manage (Matheron and Mircetich, 1985a; Mircetich and Matheron, 1983; Mircetich et al., 1998). Several commercial walnut orchards in California have been decimated because of Phytophthora crown and root rot incited by P. cinnamomi (Browne et al., 2011a; Mircetich et al., 1998). Incidence and severity of Phytophthora crown and root rots generally can be minimized by careful soil water management, use of Paradox rootstock (Mircetich et al., 1998), and treatments with phosphonate (also referred to as phosphite) (Browne et al., 2011b), but rootstocks with improved resistance to the pathogens are needed. Compared with NCB (J. hindsii) and persian walnut rootstocks, Paradox is more resistant to several species of Phytophthora (Matheron and Mircetich, 1985b; Mircetich and Matheron, 1983), but in practice this resistance has been insufficient to prevent serious losses caused by $P$. cinnamomi or P. citricola (Browne et al., 2011a; Mircetich et al., 1998). All tested open-pollinated seed families of chinese wingnut (Pterocarya stenoptera C. DC.) were highly resistant to both pathogens, but they were not graft compatible with the popular cultivar Chandler and therefore had limited usefulness as walnut rootstocks (Browne et al., 2011a).

Advances in micropropagation and breeding technologies have enabled the exploration of diverse Juglans L. species and hybrids for the improvement of walnut rootstocks (Leslie and McGranahan, 1992). The objective of this study was to identify walnut rootstock germplasm that is graft compatible with persian walnut and has high resistance to $P$. cinnamomi and $P$. citricola.

\section{Materials and Methods}

Plant materials for greenhouse trials. Forty-eight clonal and seedling selections of Juglans species and hybrids were included in greenhouse evaluations of resistance to $P$. cinnamomi and P. citricola (Table 1). All selections originated from walnut seeds, 
Breeding, Cultivars, Rootstocks, and Germplasm Resources

Table 1. Selections tested for resistance to Phytophthora species.

\begin{tabular}{|c|c|c|}
\hline \multirow[b]{2}{*}{ Genetic background } & \multicolumn{2}{|c|}{ Selections included } \\
\hline & Phase 1 experiments & Phase 2 experiments \\
\hline J. californica $\times J$. regia & $\mathrm{AX} 1, \mathrm{AX} 2$ & AX1 \\
\hline J. microcarpa, open pollinated & - & JMOP2, JMS7 \\
\hline J. hindsii $\times J$. regia & $\begin{array}{l}\text { GZ1, GZ2, GZ3, JX1, JX2, Px1, RR4cont, } \\
\text { UZ1, UZ2, VX211, Vlach }\end{array}$ & Px1 \\
\hline J. microcarpa $\times J$. regia & RX1 & RX1 \\
\hline J. microcarpa $\times$ J. regia 'Serr' & - & $\begin{array}{l}\text { 29JM10, 29JM11, 29JM12, 29JM22, } \\
\text { 29JM4, 29JM8, JMS11, JMS12, JMS13, } \\
\text { JMS15, JMS19, JMS24, JMS3, JMS5, } \\
\text { JMS5A, STJM11, STJM4, STJM6 }\end{array}$ \\
\hline$J$. nigra $\times J$. regia & CW1 & - \\
\hline Pterocarya stenoptera & Chinese wingnut seedlings ${ }^{y}$ & $\mathrm{WNxW}^{\mathrm{y}}$ \\
\hline
\end{tabular}

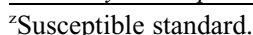

yesistant standard.

which were from open or controlled pollination of trees in the Walnut Improvement Program (WIP) collection at Davis, CA, or from the Juglans collection of National Clonal Germplasm Repository near Davis, CA. The species-level backgrounds of the clones tested in this study were determined as described previously (Potter et al., 2002). The clonal selections were chosen to provide a diverse representation of Juglans that was expected to be graft compatible with persian walnut cultivars. In addition, some of the rootstock clones had expressed one or more of the following in previous experiments: resistance to $P$. citricola (Browne et al., 2005), tolerance to Pratylenchus vulnus, the lesion nematode (Buzo et al., 2009), tolerance to Cherry leaf roll virus (McGranahan et al., 1997), or resistance to A. tumefaciens (Stover et al., 2007). Seedlings or the 'W17' clone of NCB were included as a highly susceptible standard, whereas seedlings or the 'WNxW' clone of Chinese wingnut were used as a highly resistant standard.

Clones were introduced to culture from nodal stem cuttings or zygotic embryo explants and micropropagated on Driver Kuniyuki Walnut (DKW) medium (Leslie and McGranahan, 1992). Shoots 5 to $8 \mathrm{~cm}$

Received for publication 4 Sept. 2014. Accepted for publication 2 Feb. 2015.

We are grateful to the California Walnut Board, the California Department of Food and Agriculture, and the USDA NIFA SCRI for financial support of this research. We are thankful to Bruce Mackey for statistical advice. We thank the walnut nursery industry in California for its contributions of walnut seedlings and ideas, and we are grateful to Dr. Daniel Potter for confirming identity of Paradox seedlings and clones.

Mention of a trademark, proprietary product, or vendor does not constitute a guarantee or warranty of the product by the U.S. Dept. Of Agriculture and does not imply its approval to the exclusion of other products or vendors that also may be suitable.

${ }^{1}$ Present address: Sierra Gold Nurseries, 5320 Garden Hwy, Yuba City, CA 95991.

${ }^{2}$ Corresponding author. E-mail: gtbrowne@ucdavis. edu. long were excised and induced to root on a high auxin medium before ex vitro root development under intermittent mist in either a vermiculite substrate or a well-drained peat-perlite mix. Rooted shoots were planted using 1 peat: 1 sand: 1 fir bark (by volume) potting soil in containers (Ray Leach Conetainers; Stuewe and Sons, Tangent, OR) and then acclimatized to ambient greenhouse conditions by gradually reducing ambient humidity. Established plants were repotted to larger 0.5 -L containers with 1 peat: 1 sand (by volume) University of California (UC) potting mix (Matkin et al., 1957) and grown for at least 2 additional months in a nonmisted greenhouse environment.

Greenhouse evaluations of resistance to Phytophthora. Greenhouse evaluations of resistance included two successive phases, each with multiple experiments. In addition to the standards of NCB (seedlings or 'W17') and chinese wingnut (seedlings or ' $\mathrm{WNxW}$ '), phase 1 included 24 clonal genotypes representing seven Juglans spp. hybrid backgrounds, whereas phase 2 included 23 clonal genotypes representing five Juglans spp. backgrounds (Table 1). Phase 1 included only one genotype of $J$. microcarpa Berland. $\times J$. regia, whereas phase 2 included 19 clones with this background. Clones 'AX1', 'Px1', and 'RX1' were included in both phases.

In all greenhouse trials, inocula of $P$. cinnamomi and $P$. citricola were grown on a V8 juice (the standard V8 product was used; Campbell Soup Co., Camden, NJ)-oatvermiculite substrate for 4 to 6 weeks as described previously (Matheron and Mircetich, 1985a). Two to four isolates, collected from different walnut orchards in California, were used for each species of Phytophthora in each experiment. Preference was given to recent isolates from walnut. Isolates used for P. cinnamomi included: GB647, GB3270, GB3490, GB527A, GB5971, and GB6378; and isolates used for $P$. citricola included GB5972, GB5973, GB572, GB579, GB1281, GB1572, GB5179A, GB5181, GB5781, and GB5997K. The isolates had been hyphal tipped and confirmed for identity by ITS 1 and 2 sequencing of rDNA. For each experiment, the isolates were grown individually in separate jars of substrate. Isolates of the same species were mixed in equal proportion just before inoculation. Sterile V8 juice-oatvermiculite substrate was used as the control inoculant. Just before use in greenhouse trials, all inocula and the control were rinsed in sterile deionized water to remove unassimilated nutrients.

To inoculate plants in phase 1 greenhouse experiments, each plant was lifted from its container to expose the root system and then transplanted into a 2-L pot using additional UC potting mix to fill the pot space around and slightly above the "root ball." Before the transplanting, the additional potting mix was amended with the substrate colonized by $P$. cinnamomi or $P$. citricola or the control, with each 2-L pot receiving $90 \mathrm{~mL}$ of inoculant.

In phase 2 greenhouse experiments, plants were inoculated directly in their 0.5 -L pots without transplanting. A 1-cm-wide curved spatula was used to push the UC potting mix away from the side of the pot in two opposite quadrants of the pot to a depth of $5 \mathrm{~cm}$. A $15-\mathrm{ml}$ volume of infested or sterile inoculm was then inserted into each of the spaces created by the spatula $(30 \mathrm{~mL}$ total per pot). The inoculum-filled channels were then covered with potting mix.

Phase 1 trials included 10 experiments with $P$. citricola (and the control), and five experiments with $P$. cinnamomi. Phase 2 trials included six experiments, each involving separate inoculations with $P$. cinnamomi and $P$. citricola. It was not possible to include all clonal rootstock selections in all experiments. In each phase, only rootstocks included in at least three experiments were included in data analyses and results. 'RX1' and 'AX1' occurred in all phase 1 and 2 experiments. Seedlings or 'W17' of NCB and seedlings or ' $\mathrm{WNxW}$ ' of chinese wingnut were included in: all five phase 1 experiments with $P$. cinnamomi, six phase 1 experiments with $P$. citricola, and five phase 2 experiments with $P$. cinnamomi and $P$. citricola. 
In all greenhouse experiments, treatments were arranged in a split-plot design. The inoculum treatments, including the control, were allocated randomly to mainplots, whereas rootstocks were allocated randomly to subplots. In each experiment, 10 plants were inoculated per rootstock per species of Phytophthora, and five plants per rootstock received the control. Infection by the pathogens was facilitated by soil flooding. One week after inoculation and every 2 weeks thereafter, all pots in the control and Phytophthora treatments were placed in bowls (which fit around the 2-L pots in phase 1 experiments) or cups (which fit around the 0.5 -L pots used in phase 2 experiments), and cool tap water was added to the soil to maintain the water surface at $\approx 1 \mathrm{~cm}$ above the soil surface for $48 \mathrm{~h}$. After each flooding, the pots were removed from the flooding containers and allowed to drain freely. Between soil floods, the soil was watered daily using deionized water. Soil temperatures typically ranged from 17 to $28^{\circ} \mathrm{C}$ over the course of an experiment, with a 5 to $10^{\circ} \mathrm{C}$ difference between high and low soil temperatures over a $24-\mathrm{h}$ period. The plants were fertilized weekly with modified Hoagland solution (Hoagland, 1928).

Either 3 months (phase 1 experiments) or 2 months (phase 2 experiments) after transplanting, the root systems were washed free from potting mix to assess severity of crown and root rot. For crown rot assessment, the root crown was considered to extend from the root-shoot juncture to $3 \mathrm{~cm}$ above the soil surface. On each diseased root crown, a knife was used to reveal boundaries of healthy bark (white under the outer corky layer) and necrotic bark (black to brown). A ruler was used to measure the rotted and total lengths of each root crown, and rotted crown length was expressed as a percentage of total crown length (crown rot \%). The percentage of root length rotted (root rot \%) was estimated visually; root length was considered rotted when the cortex and stele were necrotic as compared with healthy, light-colored tissues. Isolations were conducted from root systems of $40 \%$ to $60 \%$ of the plants per experiment to confirm that those grown in noninfested soil remained free from Phytophthora spp. and those grown in soil infested with $P$. cinna$m o m i$ or $P$. citricola had been exposed to the appropriate pathogen. Ten 1-cm-long segments of roots $\approx 1 \mathrm{~mm}$ in diameter were removed from each sampled root system, cultured in pimaricin-ampicillin-rifampicinpentachloronitrobenzene (PARP) medium (Kannwischer and Mitchell, 1978), incubated in the dark at $18^{\circ} \mathrm{C}$, and observed after $5 \mathrm{~d}$ for the presence of mycelium of a Phytophthora sp. Species of Phytophthora were identified according to their morphological characteristics (Erwin and Ribero, 1996) and confirmatory rDNA sequencing (ITS 1 and 2).

Field evaluation of resistance to $P$. cinnamomi. A trial was established to test the relative resistance of ' $\mathrm{RX1}$ ' and Paradox seedling rootstocks to $P$. cinnamomi under field conditions. In a commercial walnut orchard near Stockton, CA, where many trees had died with infection by $P$. cinnamomi, trees were cleared to accommodate the trial. The orchard's soil was Archerdale Clay Loam (fine silty, mixed, active, thermic typic endoaqualfs). Each former tree site in the vacant area was preplant fumigated with $0.5 \mathrm{~kg}$ methyl bromide in Fall 2009. The rootstocks were planted in Mar. 2010, 2 years after the previous trees were removed. Using a randomized complete block design, each former tree site was planted with one rootstock of ' $\mathrm{RX1}$ ' and another of Paradox seedling. The paired plants, which were ungrafted 1-year-old nursery trees, were spaced $0.6 \mathrm{~m}$ apart and in random order. The tree sites, 100 in total, were $8.5 \mathrm{~m}$ apart within and between rows. It was attempted to "bud" all of the trees to 'Serr' in Aug. 2010. Trees not successfully budded were grafted to 'Serr' in Spring 2011, and a small number of these were rebudded in Aug. 2011. The trees were irrigated with impact sprinklers according to standard commercial practice.

Resistance of the rootstocks to $P$. cinnamomi was assessed according to their survival and trunk circumference growth after three growing seasons. Trunk circumferences were measured at $30 \mathrm{~cm}$ above soil surface, and trees that died were assigned trunk circumferences of zero. Those that died in 2011 and 2012 were removed, and samples of their necrotic root and crown tissues were cultured in PARP isolation medium as described previously (Matheron and Mircetich, 1985a) to determine whether the tree death was associated with Phytophthora.

Data analyses. For data from the greenhouse trials, the MIXED procedure of SAS software Version 9.4 (Cary, NC) was used; analysis of variance (ANOVA) was conducted separately for phase 1 and phase 2 and for inoculants (i.e., P. cinnamomi, $P$. citricola, and control). In preparation, the MEANS procedure of SAS was used to generate a mean for each combination of rootstock selection, experiment, and disease assessment variable. For ANOVAs that evaluated effects of individual rootstocks (i.e., single seedling types or clones), "individual rootstock" was specified as the fixed effect in the MIXED procedure, and "experiment" was specified as the random effect. For ANOVAs that evaluated effects of "rootstock background" (i.e., species or hybrid composition), "background" was specified as the fixed effect, and "experiment" was specified as the random effect. Residuals analysis was conducted for all of the initial and final runs
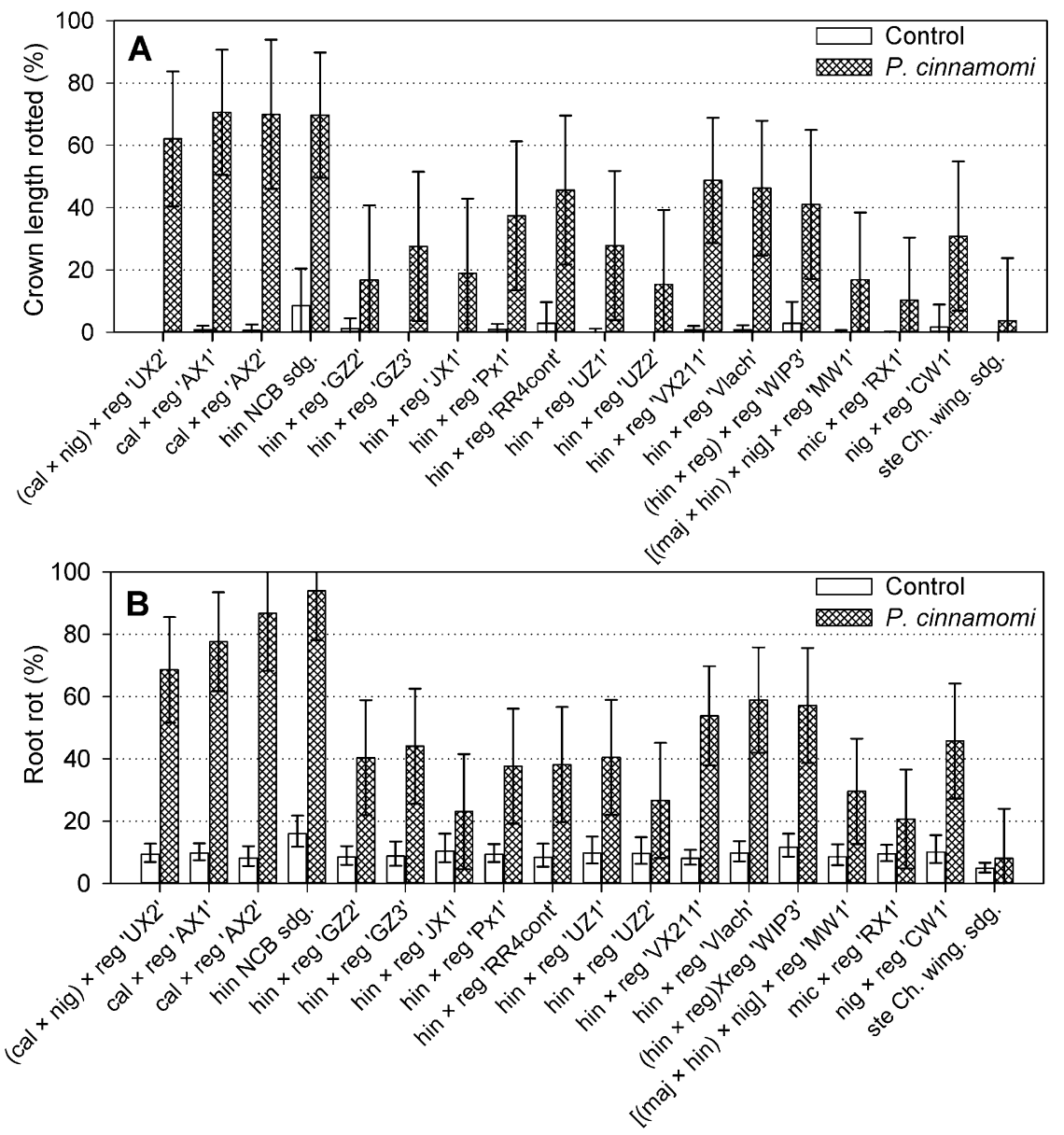

Fig. 1. Relative resistance of walnut rootstock clones to Phytophthora cinnamomi in phase 1 experiments as indicated by $\mathbf{A}$, percentage of root crown length rotted and $\mathbf{B}$, percentage of root rot. On $x$ axis, cal = Juglans californica, nig $=J$. nigra, $\mathrm{reg}=J$. regia, hin $=J$. hindsii, maj $=J$. major, mic $=J$. microcarpa, and ste = Pterocarya stenoptera . 
of the MIXED procedure to determine whether data transformation was needed to meet assumptions required for ANOVA. Accordingly, the log transformation was used with root rot $\%$ values for the control and $P$. citricola treatments. Transformation was not needed for the other variable and treatment combinations. Treatment means and their $95 \%$ confidence intervals were generated using the MIXED procedure. Transformed means and their 95\% confidence intervals were detransformed before graphical presentation. ANOVA was not feasible for crown rot $\%$ data from the control treatment, because many of the means were zeros. For the nonzero crown rot means of the control treatment, means and 95\% confidence intervals were generated using the MEANS procedure.

For data from the field trial, Fisher's exact test (Agresti, 2007) was used to compare tree survival rates on Paradox rootstock with survival rates on ' $\mathrm{RX} 1$ ' rootstock; $2 \times 2$ contingency tables specifying counts of living and dead individuals for Paradox and ' $R X 1$ ' rootstocks were evaluated. Also, using the MIXED procedure, trunk circumference increases were subjected to ANOVA, and $95 \%$ confidence intervals were generated for each rootstock's mean trunk circumference increase. In the MIXED model statement, "rootstock" was specified as the fixed effect, and "block" was the random effect.

\section{Results}

Greenhouse evaluations. In phase 1 greenhouse experiments, effects of rootstock on severity of crown and root rot were highly significant, both with $P$. cinnamomi and $P$. citricola $(P<0.0001)$. The susceptible standard, NCB seedling, developed severe crown and root rot in soil infested with either $P$. cinnamomi (mean percentages of crown and root length rotted were $70 \%$ and $94 \%$, respectively; Fig. 1) or P. citricola (97\% and $100 \%$, respectively; Fig. 2). The resistant standard, chinese wingnut seedling, developed only negligible levels of crown and root rot with either pathogen $(0 \%$ to $4 \%$ of crown length rotted, $6 \%$ to $8 \%$ root length rotted; Figs. 1 and 2). Responses of the other selections, which were all clonal hybrids among Juglans species, varied between the extremes of the standards (Figs. 1 and 2). Clone 'UX2' of ( $J$. californica $\mathrm{S}$. Watson $\times$ $J$. nigra L.) $\times J$. regia and clones 'AX1' and 'AX2' of $J$. californica $\times J$. regia were as susceptible as NCB to P. cinnamomi (Fig. 1A and B) and less susceptible than NCB to $P$. citricola (Fig. 2). In contrast, clones of $J$. hindsii $\times J$. regia and $(J$. hindsii $\times J$. regia $) \times$ $J$. regia generally were less susceptible than NCB both to $P$. cinnamomi and to $P$. citricola (Figs. 1 and 2). 'WIP 2' and 'WIP 3' were among the most susceptible clones with parents of $J$. hindsii and $J$. regia (Figs. 1 and 2). Clones 'AZ1', 'AZ2', 'AZ3', 'MW1', and 'NZ1' of $\{[J$. major (Torr.) A. Heller $\times$ $J$. hindsii $] \times J$. nigra $\} \times J$. regia developed low to moderate severities of crown and root
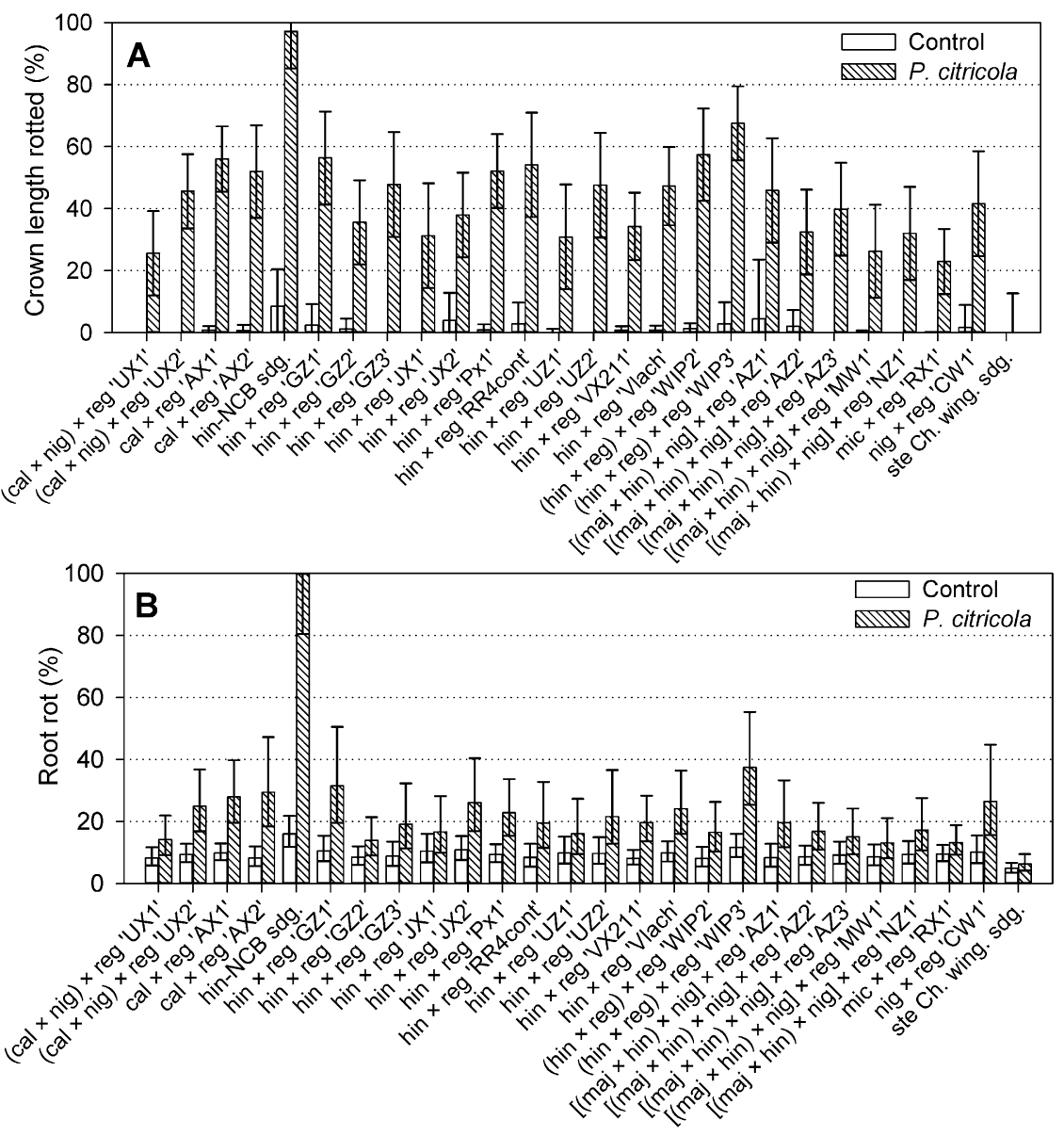

Fig. 2. Relative resistance of walnut rootstock clones to Phytophthora citricola in phase 1 experiments as indicated by $\mathbf{A}$, percentage of root crown length rotted and $\mathbf{B}$, percentage of root rot. On $x$ axis, cal $=$ Juglans californica, nig $=J$. nigra, $\mathrm{reg}=J$. regia, hin $=J$. hindsii, maj $=J$. major, mic $=J$. microcarpa, and ste $=$ Pterocarya stenoptera .

rot in soil infested with $P$. citricola, exhibiting similar levels of susceptibility as the least susceptible among $J$. hindsii $\times J$. regia clones (Fig. 2). 'MW1', the only clone of this complex interspecific background tested with $P$. cinnamomi, developed relatively low levels of crown and root rot in soil infested with the pathogen (Fig. 1). 'RX1' (J. microcarpa $\times J$. regia) exhibited relatively low susceptibility to both pathogens, while 'CW1' (J. nigra $\times J$. regia) showed low to intermediate susceptibility (Figs. 1 and 2). Noninoculated controls of the rootstocks developed very low levels of crown and root rot (Figs. 1 and 2). Isolations indicated that except in few cases, the control plants remained free from Phytophthora and plants grown in the infested treatments became infected with the appropriate species of Phytophthora. Detected incidence of Phytophthora in control plants was $<5 \%$. Cross contamination between treatments of Phytophthora was not detected, while $P$. cinnamomi and $P$. citricola typically were recovered from $>60 \%$ of sampled plants they were used to inoculate.

Species backgrounds of the clonal rootstocks tested in phase 1 affected susceptibility to $P$. cinnamomi and $P$. citricola $(P<$ 0.0001 for each pathogen and each measure of disease susceptibility; Fig. 3). Relatively high amounts of crown and/or root rot occurred with either pathogen in ( $J$. californica $\times$ $J$. nigra $) \times J$. regia, J. californica $\times J$. regia, and $J$. hindsii; whereas P. stenoptera developed negligible disease (Fig. 3). Intermediate to low levels of crown and root rot developed with $P$. cinnamomi and $P$. citricola among the other backgrounds, i.e., J. hindsii $\times$ $J$. regia, $(J$. hindsii $\times J$. regia $) \times J$. regia, $[(J$. major $\times J$. hindsii $) \times J$. nigra $] \times J$. regia, $J$. microcarpa $\times J$. regia, and $J$. nigra $\times$ $J$. regia. Susceptibility to root rot caused by $P$. cinnamomi was greater than that to root rot caused by $P$. citricola in (J. californica $\times$ $J$. nigra $) \times J$. regia and $J$. californica $\times J$. regia (Fig. 3B). The additional proportion of $J$. regia background in $(J$. hindsii $\times J$. regia $) \times$ $J$. regia was associated with greater susceptibility to $P$. citricola, compared with susceptibility in the $J$. hindsii $\times J$. regia background (crown length rotted; Fig. 3A).

In phase 2 experiments, the susceptible standard 'W17' NCB exhibited high susceptibility both with $P$. cinnamomi and $P$. citricola (49 and $77 \%$ crown length rotted, respectively), and ' $\mathrm{WNxW}$ ' chinese wingnut, the resistant standard, developed negligible disease $(5 \%$ to $8 \%$ ) (Fig. 4$)$. In the phase 2 trials as in phase 1 trials, 'AX1' had high 

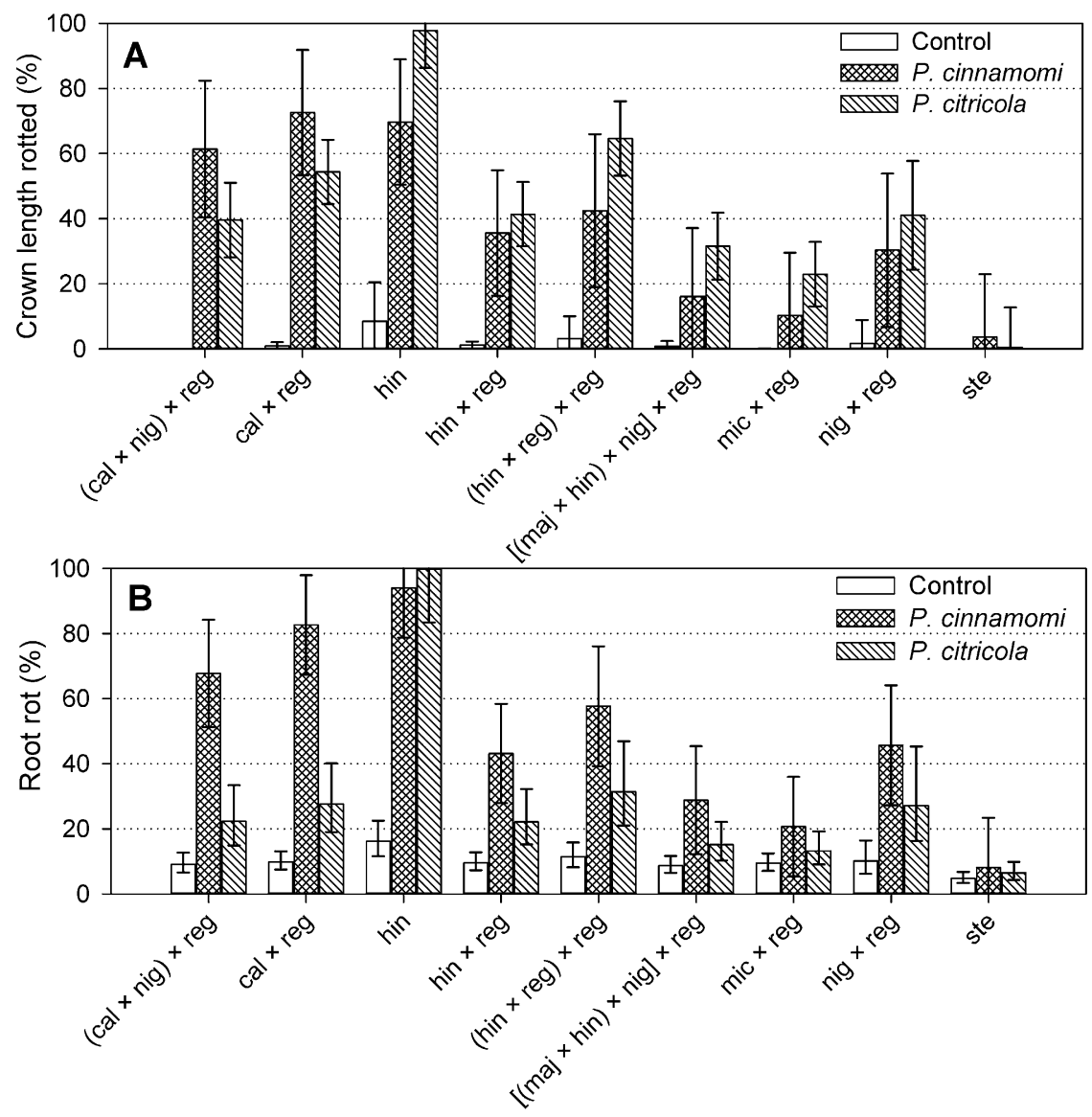

Fig. 3. Relative resistance of species backgrounds of walnut rootstocks to species of Phytophthora in phase 1 experiments as indicated by $\mathbf{A}$, percentage of root crown length rotted and $\mathbf{B}$, percentage of root rot. On $x$ axis, cal $=$ Juglans californica, nig $=J$. nigra, reg $=J$. regia, hin $=J$. hindsii, maj $=J$. major, mic $=$ $J$. microcarpa , and ste $=$ Pterocarya stenoptera .

susceptibility to both pathogens. 'Px1' was among the most susceptible clones to $P$. cinnamomi and $P$. citricola, similar in susceptibility to 'W17'. Clones 'JMOP2' and 'JMS7' of $J$. microcarpa, and the 19 clones of $J$. microcarpa $\times J$. regia and J. microcarpa $\times$ $J$. regia 'Serr' showed low to intermediate susceptibility to crown and root rot with $P$. cinnamomi; however, most of them (e.g., 'JMOP2', 'JMS7', 'RX1', '29JM11', '29JM12', '29JM22', '29JM4', 'JMS13', 'JMS24', 'JMS5', 'JMS5A', 'STJM11', and 'STJM6') were moderately susceptible to $P$. citricola crown rot (Fig. 4). The J. microcarpa $\times J$. regia 'Serr' clones '29JM8' and 'STJM4' exhibited low susceptibility to both pathogens.

Species backgrounds of rootstocks in phase 2 significantly affected their susceptibility to Phytophthora (Fig. 5; $P=0.002$ and $P<0.0001$ for crown and root rot, respectively, caused by $P$. cinnamomi; $P<0.0001$ for crown and root rot caused by $P$. citricola). Backgrounds of $J$. californica $\times J$. regia, $J$. hindsii, and $J$. hindsii $\times J$. regia exhibited high to moderate susceptibility to $P$. cinnamomi and $P$. citricola (Fig. 5). The J. microcarpa, J. microcarpa $\times J$. regia, and $J$. microcarpa $\times J$. regia 'Serr' backgrounds generally exhibited low susceptibility to $P$. cinnamomi and high-to-intermediate susceptibility to $P$. citricola, compared with the resistant standard of $P$. stenoptera (Fig. 5).

Field evaluation. In the field trial conducted where $P$. cinnamomi had killed many trees in a commercial orchard, 58 pairs of 'RX1' and Paradox seedling trees were successfully budded to 'Serr' in Fall 2010 (Table 2, set 1). Another 19 of the pairs had one of the trees budded in Fall 2010 and the other grafted in Spring 2011 (Table 2, set 2). Fall 2010 budding and Spring 2011 grafting were considered to be similar scenarios, because in each case shoot growth emerged from the scion in Spring 2011. In set 1, all 'Serr'/'RX1' trees survived and looked healthy at 3 years after planting (at the experiment's conclusion), whereas only 35 of 58 'Serr'/Paradox trees survived (Table 2). The mean increase in trunk circumference on 'RX1' was nearly 5-fold greater than that on Paradox seedling (Table 2, set 1). Results were similar for set 2; all 19 'Serr'/'RX1' trees were healthy at the end of the experiment, whereas only three of 19 'Serr'/ Paradox trees survived (Table 2). Over the experimental period, 'Serr'/'RX1' trunk circumference increases in set 2 were similar to those in set 1 , but there was a net loss in living trunk circumference for 'Serr'/Paradox trees in set 2 (Table 2). Fisher's exact tests indicated that differences in survival on ' $\mathrm{RX1}$ ' and Paradox seedling rootstocks were highly significant $(P<0.0001$, Table 2$)$.

\section{Discussion}

To our knowledge, this is the first fieldvalidated report of high resistance to $P$. cinnamomi in the genus Juglans. Using controlled greenhouse experiments with conditions highly conducive to infection by Phytophthora species, we determined that the 'RX1' clone of $J$. microcarpa $\times J$. regia exhibited high resistance to $P$. cinnamomi and moderate resistance to $P$. citricola. The resistance of ' $\mathrm{RX} 1$ ' to $P$. cinnamomi was confirmed in an area of a commercial walnut orchard decimated from infection by the pathogen. There, replicate trees of 'Serr' walnut grafted or budded on ' $\mathrm{RX} 1$ ' remained healthy and grew satisfactorily, while trees of 'Serr' on Paradox seedling, presently the commercial rootstock standard in California, suffered high mortality rates and grew poorly. 'RX1' appears to have good graft compatibility among cultivars of persian walnut (C. Leslie, unpublished data), but long-term horticultural assessments of ' $\mathrm{RX1}$ ' are needed. ' $\mathrm{RX} 1$ ' has been patented for use as a walnut rootstock, primarily because of its moderate resistance to $P$. citricola (McGranahan et al., 2010). The results reported here confirm the patented moderate resistance to $P$. citricola and significantly expand documentation of resistance to include $P$. cinnamomi, known as the most aggressive and destructive pathogen on walnut worldwide (Belisario et al., 2009). ' $\mathrm{RX1}$ ' is considered to be appropriate for cultivation of persian walnut on sites infested with $P$. cinnamomi.

In previous work, chinese wingnut was highly resistant to both $P$. cinnamomi and $P$. citricola, and the resistance to $P$. cinnamomi was confirmed in a commercial orchard infested with the pathogen (Browne et al., 2011a). However, chinese wingnut was graft incompatible with some important walnut cultivars, including Chandler, the most widely grown persian walnut in California (Browne et al., 2011a). Among Juglans spp., excised shoots of J. hindsii, $J$. nigra, and $J$. mandshurica Maxim. offered greater resistance than shoots of J. regia and J. sieboldiana Maxim. (=J. ailantifolia Carriere var. ailantifolia) to $P$. cinnamomi (Belisario et al., 2009), but intact seedlings of $J$. ailantifolia, J. hindsii, and J. nigra, grown in a potting soil infested with $P$. cinnamomi or P. citricola in a greenhouse, were susceptible to both pathogens and developed severe crown and root rot (Matheron and Mircetich, 1985b). The latter assessments found J. microcarpa to be highly susceptible to $P$. citricola.

Not all of the clonal selections or genetic backgrounds were evaluated for resistance in both phase 1 and phase 2 greenhouse experiments, but the selections that were included in both phases generally gave consistent responses. Across both phase 1 and 2 of testing, 

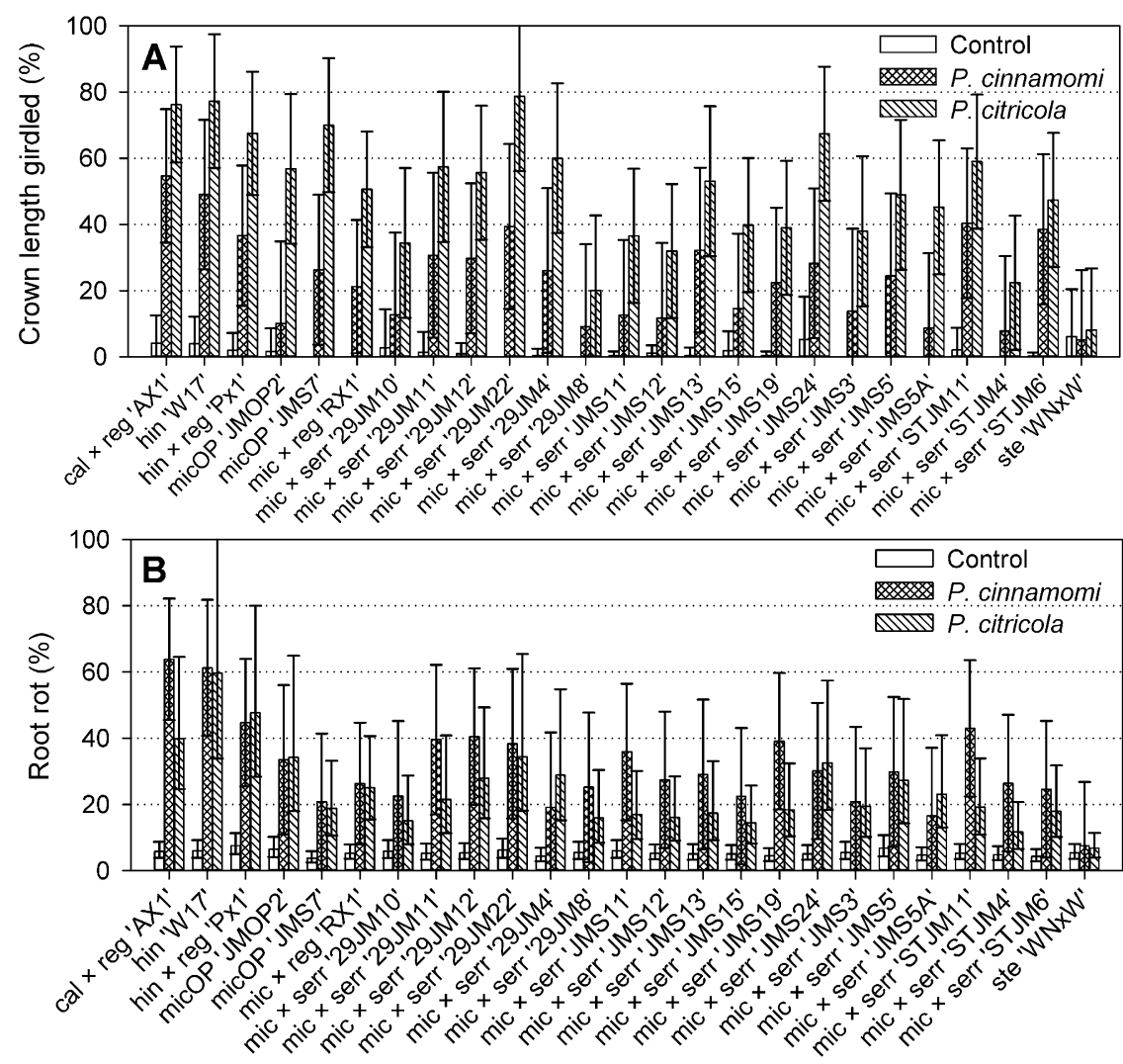

Fig. 4. Relative resistance of walnut rootstock clones to species of Phytophthora in phase 2 experiments as indicated by $\mathbf{A}$, percentage of root crown length rotted and $\mathbf{B}$, percentage of root rot. On $x$ axis, cal $=$ Juglans californica, reg $=J$. regia, hin $=J$. hindsii, micOP $=J$. microcarpa open pollinated, serr $=$ $J$. regia 'Serr', and ste = Pterocarya stenoptera .
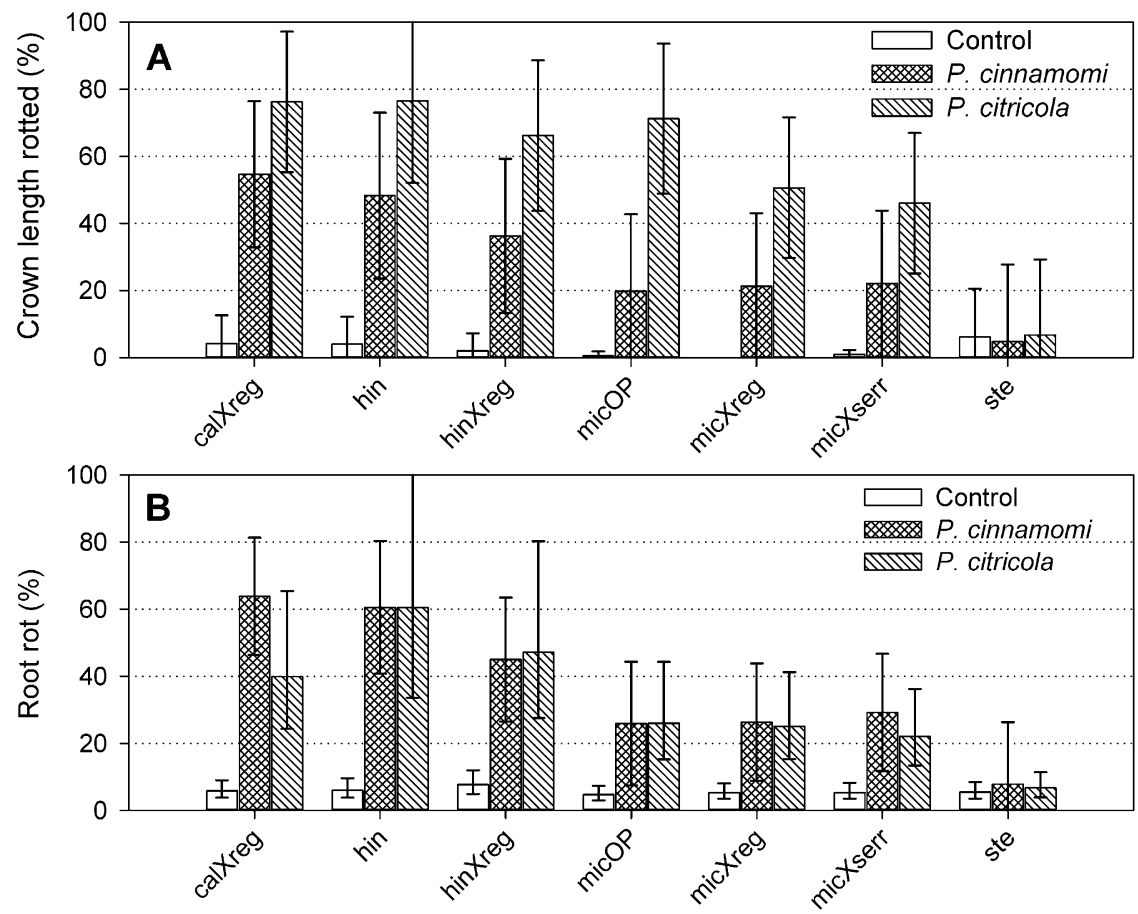

Fig. 5. Relative resistance of species backgrounds of walnut rootstocks to species of Phytophthora in phase 2 experiments as indicated by $\mathbf{A}$, percentage of root crown length rotted and $\mathbf{B}$, percentage of root rot. On $x$ axis, cal $=$ Juglans californica, reg $=J$. regia, hin $=J$. hindsii, micOP $=J$. microcarpa open pollinated, serr $=J$. regia 'Serr', and ste $=$ Pterocarya stenoptera .
J. californica $\times J$. regia 'AX1' had high susceptibility to both pathogens, $J$. microcarpa $\times$ $J$. regia ' $\mathrm{RX} 1$ ' had relatively low susceptibility to $P$. cinnamomi and intermediate susceptibility to $P$. citricola, and $J$. hindsii $\times$ $J$. regia 'Px1' had intermediate susceptibility to $P$. cinnamomi and intermediate to high susceptibility to $P$. citricola. In addition, seedlings and 'W17' of NCB were consistently highly susceptible to both pathogens while seedlings and ' $\mathrm{WNxW}$ ' of $P$. stenoptera were highly resistant.

Evaluating resistance to Phytophthora among numerous and diverse walnut germplasm selections was challenging, even in a greenhouse setting. Of special concern were potential differential interactions between walnut genotypes and environmental conditions of the greenhouse that may lessen precision and accuracy of the resistance assessments. For example, seasonal effects, which can greatly affect susceptibility to Phytophthora in walnut rootstocks, must be carefully managed (Matheron and Mircetich, 1985c). The orchard results of our study provided critical validation for greenhouse results.

In phase 2 of the greenhouse experiments, we determined that high resistance to $P$. cinnamomi was present in many, but not all clones of $J$. microcarpa $\times J$. regia 'Serr'. Furthermore, from this genetic background, '29JM8' and 'STJM4' expressed high resistance to both $P$. citricola and $P$. cinnamomi, while other clones of J. microcarpa $\times$ $J$. regia 'Serr' had moderate-to-high susceptibility to one or both of the pathogens. Apparently, although $J$. microcarpa $\times$ $J$. regia hybrids can possess high resistance to both $P$. cinnamomi and $P$. citricola, such resistance is not universal among such clones. Although it should be possible to identify additional clones of $J$. microcarpa $\times J$. regia 'Serr' with good resistance to both pathogens, screening would be required to accomplish this. Identifying such clones would increase the probability of finding rootstocks that resist not only Phytophthora but also other soilborne pathogens. Resistance to multiple soilborne pathogens combined with good horticultural adaptation is a goal of current walnut rootstock research in the WIP at UC Davis. Interestingly, some, but not all clonal and seedling selections of $J$. microcarpa and $J$. microcarpa $\times J$. regia are resistant to crown gall caused by $A$. tumefaciens (Kluepfel et al., 2012). Clones '29JM8' and 'STJM4'will be examined further as potential rootstocks.

In our phase 2 greenhouse experiments, we found resistance to $P$. cinnamomi in both tested clones of $J$. microcarpa ('JMOP2' and 'JMS7'). The fact that the $J$. microcarpa clones expressed similar levels of resistance to $P$. cinnamomi as did the $J$. microcarpa $\times$ $J$. regia hybrids suggests that at least a portion of the resistance expressed in the hybrids originated from $J$. microcarpa. Such resistance has not been detected in $J$. regia (Matheron and Mircetich, 1985b; Mircetich et al., 1998). 
Table 2. Performance of 'RX1' and Paradox seedling rootstocks in a commercial orchard infested with Phytophthora cinnamomi ${ }^{2}$.

\begin{tabular}{|c|c|c|c|c|}
\hline \multirow[b]{2}{*}{ Set, budding/grafting date } & \multirow[b]{2}{*}{ Rootstock } & \multicolumn{2}{|c|}{$\begin{array}{l}\text { No. of surviving trees/total } \\
\text { number of trees }\end{array}$} & \multirow{2}{*}{$\begin{array}{l}\text { Mean increase in trunk } \\
\text { circumference }(\mathrm{cm})^{\mathrm{x}}\end{array}$} \\
\hline & & Initial & Final & \\
\hline \multirow{2}{*}{1, Fall 2010} & Paradox & $58 / 58$ & $35 / 58$ & $4.6(2.9-6.3)$ \\
\hline & RX1 & $58 / 58$ & $* 58 / 58 *$ & $21.8(20.1-23.5)$ \\
\hline \multirow[t]{2}{*}{ 2, Fall 2010/Spring 2011} & Paradox & $19 / 19$ & $3 / 19$ & $-1.9(-4.0-0.2)$ \\
\hline & RX1 & $19 / 19$ & *19/19* & $22.1(20.0-24.3)$ \\
\hline
\end{tabular}

${ }^{\mathrm{z}}$ Trees on Paradox seedling and RX1 rootstocks were planted in matched pairs at former tree sites in a cleared portion of an orchard infested with $P$. cinnamomi.

${ }^{\mathrm{y}}$ Within a column, ratios bracketed by asterisks differ significantly from those of the Paradox standard in the same set $(P<0.05$, Fisher's exact test). Initial tree status was in first growing season, and final tree status was at end of experiment in the third growing season.

${ }^{x}$ Values in parentheses indicate $95 \%$ confidence intervals.

Among hybrids of Juglans species evaluated here, we found no greater resistance to $P$. cinnamomi or $P$. citricola than that among hybrid clones of $J$. microcarpa $\times J$. regia. However, additional examinations of some of the other backgrounds may be justified for other desirable attributes. For example, although 'AX1' and 'AX2' (J. californica $\times$ $J$. regia) were both highly susceptible to $P$. cinnamomi and $P$. citricola, 'AX1' was relatively resistant to $A$. mellea in tissue cultures (Baumgartner et al., 2013) and seems worthy of orchard testing for this trait. Also, because of limited plant numbers, we were unable to evaluate resistance to $P$. cinnamomi in ' $U X 1$ ' $(J$. californica $\times J$. nigra $) \times J$. regia; 'GZ1' and 'JX2' (J. hindsii $\times$ J. regia), 'WIP2' $[(J$. hindsii $\times J$. regia $) \times J$. regia $)]$; and 'AZ1', 'AZ2', 'AZ3', and 'NZ1' $\{[(J$. major $\times$ $J$. hindsii $) \times J$. nigra $] \times J$. regia $\}$; evaluations of the resistance may be justified for some of these selections. The latter species hybrid background has not been examined further because of a tendency for poor survival when transplanted as "bare root" trees from the nursery (C. Leslie et al., unpublished data). Seedling rootstocks representing most Juglans species and hybrid backgrounds included in this study were tested in previous orchard trials (Beede et al., 2007) and were graft compatible with persian walnut, but additional research would be needed to fully evaluate compatibility of the clones tested here. It is likely that all selections tested here would be hypersensitive to Cherry leaf roll virus (i.e., and therefore subject to walnut blackline disease), but confirmation of this trait would require further testing. In previous research, trees of 'Serr'/J. microcarpa seedling grew and yielded acceptably on a clay loam soil but performed poorly on a sandy loam soil (Browne et al., 1977).

In addition to the practical potential they offer for management of Phytophthora in walnut orchards, rootstocks such as 'RX1' and others derived from J. microcarpa and its hybrids may prove valuable for further genetic examinations. For example, the fact that not all clones derived from J. microcarpa $\times$ $J$. regia expressed high resistance to $P$. cinnamomi and $P$. citricola suggests that DNA sequence-based "mapping" of segregating resistance factor(s) may be possible.
Also, the fact that $J$. microcarpa clones were as resistant as $J$. microcarpa $\times J$. regia clones to $P$. cinnamomi, whereas only $J$. microcarpa $\times$ $J$. regia clones were also resistant to $P$. citricola suggests that heterosis effects may contribute to the P. citricola resistance. Juglans regia, like $J$. microcarpa, is considered as susceptible to $P$. citricola (Matheron and Mircetich, 1985b). Efficient development of walnut rootstocks with resistance to multiple soilborne pathogens could be facilitated by resistance mapping technologies and knowledge of potential heterosis effects.

\section{Literature Cited}

Agresti, A. 2007. An introduction to categorical data analysis. John Wiley \& Sons, New York, NY.

Baumgartner, K., P. Fujiyoshi, G.T. Browne, C.A. Leslie, and D.A. Kluepfel. 2013. Evaluating Paradox walnut rootstocks for reistance to Armillaria root disease. HortScience 48: 68-72.

Beede, B., R. Buchner, J. Grant, W. Reil, B. Lampinen, J. Hasey, G. McGranahan, C. Leslie, D. Ramos, J. McKenna, S. Metcalf, C. Negron, C. Gilles, and L. Humphreys. 2007. Paradox diversity study: Orchard trials 2007. California Walnut Board.

Belisario, A., M. Galli, and E. Wajnberg. 2009. Evaluations of Juglans species for resistance to Phytophthora cinnamomi: Differences in isolate virulence and response to fosetyl-Al. For. Path. 39:168-176.

Browne, G.T., J.A. Grant, L.S. Schmidt, C.A. Leslie, and G.H. McGranahan. 2011a. Resistance to Phytophthora; and graft compatibility with Persian walnut among selections of Chinese wingnut. HortScience 46:371-376.

Browne, G.T., S.T. McLaughlin, W.P. Hackett, G.H. McGranahan, and C.A. Leslie. 2005. Evaluation of resistance to Phytophthora citricola among diverse clones of Paradox hybrid rootstocks. Acta Hort. 705:395-400.

Browne, G.T., T.L. Prichard, L.S. Schmidt, and W.H. Krueger. 2011b. Evaluation on phosphonate treatments for control of Phytophthora crown rot of walnut. Plant Health Prog., doi: 10.1094/PHP-2011-0601-RS.

Browne, L.T., L.C. Brown, and D.E. Ramos. 1977. Walnut rootstocks compared. Calif. Agr. 31:14-16.

Buzo, T.S., A. Anwar, S. Kaku, J. McKenna, and M. McKenry. 2009. VX211, a vigorous new walnut hybrid clone with tolerance and a useful resistance mechanism. J. Nematol. 41:211-216.
Erwin, D.C. and O.K. Ribero. 1996. Phytophthora diseases worldwide. APS Press, St. Paul, MN.

Hoagland, D. 1928. The water-culture method for growing plants without soil. University of California, College of Agriculture, Agricultural Experiment Station, Berkeley, CA.

Kannwischer, M.E. and D.J. Mitchell. 1978. The influence of a fungicide on the epidemiology of black shank of tobacco. Phytopathology 68: 1760-1765.

Kluepfel, D., A. Aradhya, A. McClean, J. Moersfelder, L. Curiel, and W. Hackett. 2012. Identification and characterization of crown gall resistant Juglans germplasm, p. 413-418. In: D. Ramos (ed.). Walnut Research Reports, California Walnut Board. <http://ucanr.edu/repositoryfiles/ 2012_413_ocr.pdf-154595.pdf $>$.

Leslie, C. and G. McGranahan. 1992. Micropropagation of Persian walnut, p. 136-150. In: Y. Bajaj (ed.). Biotechnology in agriculture and forestry: High tech and micropropagation II. Springer Verlag, Berlin, Germany.

Matheron, M.E. and S.M. Mircetich. 1985a. Pathogenicity and relative virulence of Phytophthora spp. from walnut and other plants to rootstocks of English walnut trees. Phytopathology 75:977-981.

Matheron, M.E. and S.M. Mircetich. 1985b. Relative resistance of different rootstocks of English walnut to six Phytophthora spp. that cause root and crown rot in orchard trees. Plant Dis. 69:1039-1041.

Matheron, M.E. and S.M. Mircetich. 1985c. Seasonal variation in susceptibility of Juglans hindsii and Paradox rootstocks of English walnut trees to Phytophthora citricola. Phytopathology 75:970-972.

Matkin, O.A., P.A. Chandler, and K.F. Baker. 1957. The U.C.-Type Soil Mixes, p. 68-85. In: K.F. Baker (ed.). UC system for producing healthy container-grown plants. University of California, Berkeley, CA.

McGranahan, G., G. Browne, C. Leslie, W. Hackett, and J. McKenna. 2010. Walnut rootstock 'RX1'. U.S. Plant Patent No. US PP20,649 P3. Date of patent: 19 Jan. 2010.

McGranahan, G.H. and P.B. Catlin. 1987. Juglans rootstocks, p. 411-450. In: R.C. Rom and R.F. Carlson (eds.). Rootstocks for fruit crops. John Wiley \& Sons, New York, NY.

McGranahan, G.H., C.A. Leslie, and K.E. Woeste. 1997. Backcross breeding walnuts for resistance to the cherry leafroll virus. Acta Hort. 442:121-128.

Mircetich, S.M., G.T. Browne, M.E. Matheron, and B.L. Teviotdale. 1998. Armillaria and Phytophthora root and crown rot diseases, p. 221-232. In: D.E. Ramos (ed.). Walnut Production Manual. University of California, Oakland, CA.

Mircetich, S.M. and M.E. Matheron. 1983. Phytophthora root and crown rot of walnut trees. Phytopathology 73:1481-1488.

Potter, D., F. Gao, S. Baggett, J.R. McKenna, and G.H. McGranahan. 2002. Defining the sources of Paradox: DNA sequence markers for North American walnut (Juglans L.) species and hybrids. Sci. Hort. 94:157-170.

Stover, E., M. Maccree, A. Aradhya, A. McClean, and D. Kluepfel. 2007. Evaluation of wild Juglans species for crown gall resistance, $\mathrm{p}$. 231-236. In: D. Ramos (ed.). Walnut Research Reports, California Walnut Board. <http://ucanr. edu/repositoryfiles/2007_231_ocr.pdf-154456. pdf $>$. 